\title{
APPLICATION OF TVAC-PSO FOR REACTIVE POWER COST MINIMIZATION IN DEREGULATED ELECTRICITY MARKETS
}

\author{
K Rajitha Nair ${ }^{1}$, Vara Prasad Janamala ${ }^{2}$ \\ ${ }^{1}$ PG Scholar, Electrical and Electronics Department, Christ University Faculty of Engineering, Karnataka, India \\ ${ }^{2}$ Faculty, Electrical and Electronics Department, Christ University Faculty of Engineering, Karnataka, India
}

\begin{abstract}
For planning and proper operation of power system, optimization of reactive power is a must. The reactive power cost minimization aims at dispatching the reactive power in such a way that maximum real power is dispatched and minimum reactive power is utilized so that voltage is maintained at required level. The work presented in this paper discusses various loading conditions and the improvement after applying the optimization technique. It compares the reactive power cost both before and after optimally dispatching the reactive power and thereby ensuring the voltage stability of the power system. Optimal power dispatch is solved using Time Varying Acceleration Coefficient and Particle Swarm Optimization. Reactive support of the generators has two functions such as voltage control and real power delivery. It explains how the application of PSO helps in reactive power control and reduction in power losses.
\end{abstract}

Keywords: Ancillary services, Deregulated Electricity Market, Optimal Reactive Power Dispatch. $* * *$

\section{INTRODUCTION}

The modern day power systems are required or forced to operate much closer to their stability limits due to the increased demand for electric power by the loads. In such a stressed situation, the system may have voltage instability problems and thus may lead to the problem of voltage collapse and in some cases has led to system blackouts in many countries across the world [1]. One of the main reasons for voltage instability is the insufficient reactive power support [2]. Generation, distribution and transmission have been unbundled into separate businesses and thus the power industry has changed drastically due to development of the competitive markets for trading the wholesale power by deregulation. And reactive power became one of the ancillary services. [3]. Generation and transmission cannot do anything without reactive power, which is definitely the poorly understood but very important part of electricity. It was believed that these competitive markets may lead to a highly efficient generation of power, there will be more technological innovations and the rate of power may go down but due to the environmental aspects and economic constraints the power system became more and more complex and was forced to operate near to their limits [1] [2]. Researchers and system operators has always been keenly interested to study the optimal dispatch of reactive power, especially after the deregulation of the power industry. Reactive power and bus voltages are related to each other throughout the network, and hence reactive power services plays an important role in the system security [4], [5]. Voltage instability may lead to voltage collapse. Voltage collapses usually occur on power system which are faulted or heavily loaded or have shortage of reactive power [5]. Management of reactive power resources is vital for stable and secure operation of power systems in the view point of voltage stability [1]. Reactive power dispatch is one of the important tasks in the operation and control of power system. Insufficient reactive power supply has resulted in one of the major blackouts of all time that is the US-Canada Power System Outage Task Force states in its report that insufficient reactive power was an issue in the August 2003 blackout [4]. In deregulated electricity markets, reactive power dispatch is related to the short-term allocation of reactive power as required from suppliers based on present operating conditions. The Independent System Operator is concerned with determining the optimal reactive power schedule for all providers based on a given objective that depends on system operating criteria. Different objective functions can be used by the Independent System Operator, besides the usual transmission losses minimization, such as reactive power cost minimization, minimizing the cost of adjusting reactive power control devices, or maximization of system loadability to minimize the risk of voltage collapse.

The reactive power cost production from a synchronous generator is divided into two main cost components they are the fixed cost and the variable operating cost. [8] The fixed cost represents a part of the generator's capital cost which goes toward providing reactive power; hence, it is very difficult to separate this fixed cost component from the total plant capital cost. The variable cost consist of two important components: the first component emerge from the increased losses in the armature and field windings of the generator because of an increase in its reactive power output, and the second component is associated with the cost of opportunity lost if the generator is required to reduce its real power generation in order to meet the reactive power requirements assigned by the ISO. [3] 


\section{REACTIVE POWER OPTIMIZATION}

Reactive power is a quantity which is defined with alternating current systems. There are different types of electrical loads and they are classified into different categories on basis of various factors. Depending upon the nature of load we have resistive loads, capacitive loads, inductive loads and combination of above said three. If the loads are capacitive type or inductive type or the combination of both, the current and voltage will not be in phase or in other words either the current will be leading the voltage if the load is capacitive or the current will be lagging the voltage if the load is inductive in nature and in such conditions the reactive power is produced [1] [6.] Here only the current component in phase with the voltage produces the real power. Reactive power is the reason for electric field and magnetic field in capacitors and inductors. It is the circulating power in the system that does no work. It is one of the ancillary services in the deregulated electricity market [1]. Two major requirements of reactive power are by the reactive power consumers and for system requirements and its consumption depends upon the load factor.

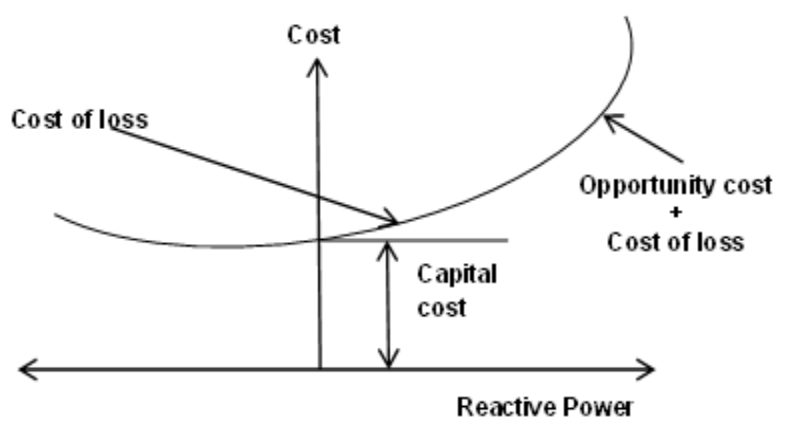

Fig -1: Cost of reactive power from a synchronous generator

For proper operation of electrical equipment voltage regulation is necessary. Proper operation of electrical power equipment means there should not be any overheating of generators or motors, and then it should be able to minimize the losses and to make the system stable so that it does not collapse.[3] Reactive power is necessary to maintain the rated voltage at all the buses in order to deliver active power to the sending end or the loads through the transmission lines. Some of the loads like motor loads need the reactive power to do the useful works as it converts the flow of electrons for desired work. Absence of required reactive power may lead to the fall of bus voltage below its rated value and thereby the power required by the loads may not be provided [5]. If the voltage on the system is not sufficient due to insufficient reactive power required active power cannot be supplied by the system. An effective management of reactive power should take care of three important requirements they are [10]:

- It should maintain the rated voltages at all the buses within the desired levels both at normal conditions and contingency conditions.
- To maintain the system stability and to utilize the transmission lines to its maximum [14] I order to prevent voltage collapse.

- $\quad$ To minimize power losses and thereby increasing the efficiency.

It is necessary to keep the terminal voltages of all the equipment in utility side and customer side within an acceptable range [4]. If the equipment on either side (utility and consumer) operates at a voltage below or above the rated voltage for a long time then the equipment performance will be affected or there is a good chance of equipment getting damaged. The difficulty of maintaining voltages within the required limits is difficult because of the fact that in power systems, the power system supplies power to a large number of loads and that is supplied from different generating stations. The generating station produces both active and reactive power [1]. If reactive power generation is decreased there is a fall in the system voltage and if the reactive power is increased the system voltage increases. When the system tries to provide more load than the voltage can support the voltage collapse happens [7]. If the system voltage falls the current must be increased in order to keep the required power demand and thereby causing the system to consume more reactive power causing the voltage to drop further [2]. If the current increases, transmission losses will increase and if the voltage drops to very small values, some generators will automatically disconnect itself for protection purpose and thereby decreasing the system voltage to further low levels which may lead to tripping of circuits and ultimately to system collapse so proper reactive power support is necessary. The problem of optimal reactive power dispatch is considered as part of optimal power flow problem.[6].If we add some controllable variable of reactive power compensators to the economic dispatch problem real power dispatch problem then it can be used to determine the optimal reactive power dispatch problem. The Optimal Power Flow consists of two sub problem they are the economic dispatch and the optimal reactive power dispatch. They are solved until their convergence is reached. The main aim of modeling objective function is to reduce the real power losses when they are modeled for solving optimal reactive power dispatch. Reactive power cost minimization is mainly in done in terms of system losses.[1]-[7].The aim of optimal power dispatch is to reduce the overall fuel cost under certain constraints.

$$
\operatorname{Min}_{P_{G, i}, V_{G, i}} . \text { Cost }=P_{\text {price }} *\left[\sum_{i=1}^{n}\left(P_{G, i}\right]\right.
$$

The reactive power cost is calculated from the obtained load flow studies and is compared for its rate before and after applying PSO. The cost for reactive power is calculated using the expression which is similar to the load dispatch calculation formulae and it is represented by the equation:

$$
\text { Cost }_{\text {reactivepower }}=a_{1} Q^{2}+b_{1} Q+c 1
$$


Where,

$a_{1}=a \sin ^{2} \theta$

$b_{1}=b \sin \theta$ and,

$c_{1}=c$

$a, b, c$ are the cost coefficients.

Reactive power is a must to run many electrical devices, but it can cause several harmful effects on different appliances and other motorized equipment's or loads, as well as the entire electrical infrastructure [5]. As the current passing through the electrical system is higher than the required amount to do the necessary work, excess power is dissipated in the form of heat because the reactive current flows through various resistive components like wires, switches and transformers. Keeping in mind the fact that when energy is expended, we need to pay. It does not make any difference whether the energy is utilized in the form of heat or useful work. We can determine the amount of reactive power used by the electrical devices by measuring their pf (power factor) which is the ratio between real power and true power. A pf 1 means that all the electrical power is applied towards real work that is the ideal situation.

\section{TVAC-PSO}

The problem of optimal power dispatch is highly nondifferentiable, highly non-linear and discontinuous function and hence Time Varying Acceleration Coefficient - Particle Swarm Optimization is used to solve the real and reactive power optimal dispatch. It is search algorithm which is very helpful in solving nonlinear problems without placing any restriction on the shape of the objective function [1]. It includes Initialization, power flow analysis, evaluation of the fitness function, updating the particles and updating the best particles. The advantage of using this algorithm is that it requires minimum number of variables required for making decision. Main required thing is the power flow analysis. Only disadvantage of this search is that it requires huge calculation time.

The updating equations of TVAC-PSO are expressed as:

$V_{i}^{k+1}=\omega^{k} * V_{i}^{k}+a_{1} * \operatorname{rand}_{1}\left(\mathrm{P}_{\text {best }, i}^{k}-\mathrm{X}_{i}^{k}\right)+\mathrm{a}_{2}{ }^{*} \operatorname{rand}_{2}\left(\mathrm{G}_{\text {best }}^{k}-\mathrm{X}_{i}^{k}\right)$

Where,

$$
\begin{aligned}
& \omega^{k}=\omega_{\max }-\frac{\omega_{\text {max }}-\omega_{\min }}{k_{\max }} * k \\
& a_{i}^{k}=a_{i, \max }-\frac{a_{i, \max }-a_{i, \min }}{k_{\text {max }}} * k \\
& X_{i}^{k+1}=X_{i}^{k}+V_{i}^{k+1}
\end{aligned}
$$

The optimal dispatch problem solution using PSO follows the given flowchart given in the figure below.

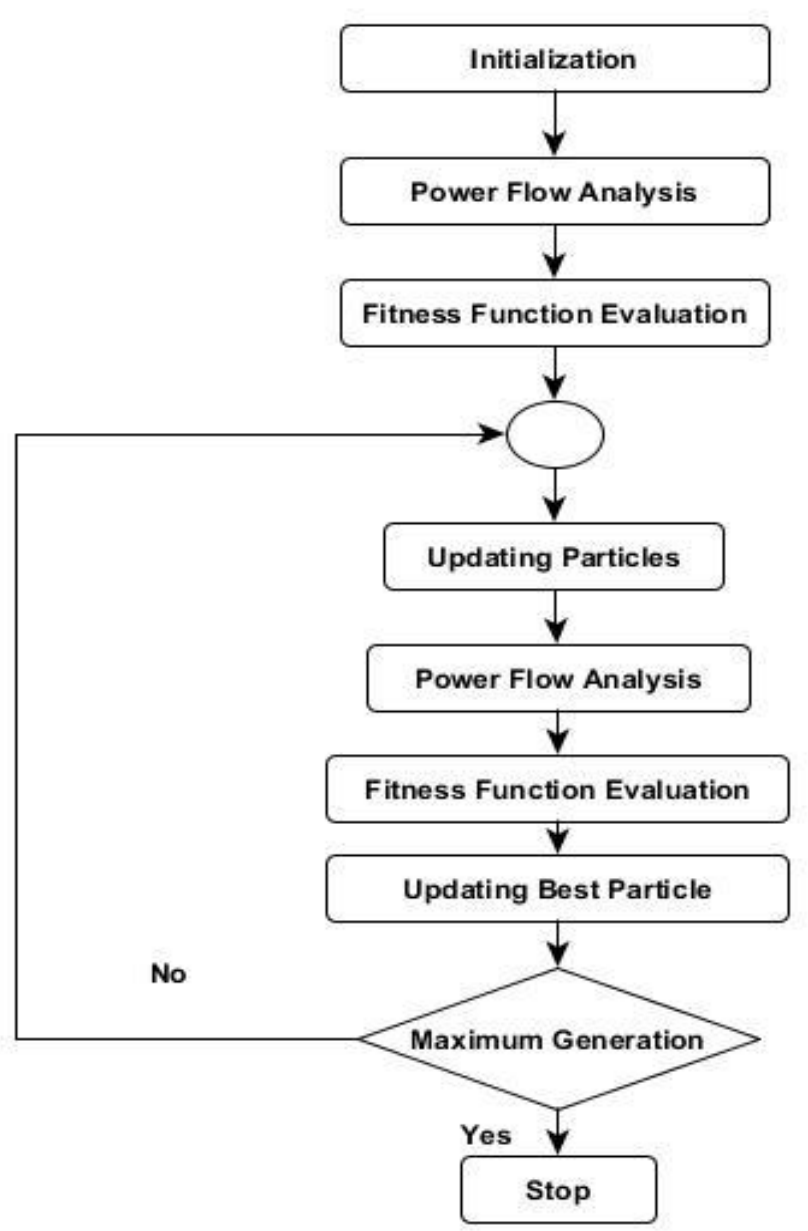

Fig -2: Optimal power dispatch in TVAC-PSO

\section{IMPLEMENTATION AND RESULTS}

\section{IEEE14 Bus System}

\section{Case (i): Base Loading Condition:}

When the incremental cost is $39 \$ / \mathrm{MWh}$ and the optimal dispatch of generation is $274.726 \mathrm{MW}$. The table I shows the comparison before and after applying PSO at the generators $1,2,3,6$ and 8 when the cost coefficients are, $a=0.04303$, $\mathrm{b}=20$ and $\mathrm{c}=\mathrm{O}$ at the $8^{\text {th }}$ hour and when none of the loads has exceeded its normal limit value.

Table 1: Comparison of active and reactive power at base load condition

\begin{tabular}{|l|l|l|l|l|l|l|}
\hline Generator & \multicolumn{2}{|l|}{ Before Applying PSO } & \multicolumn{3}{|l|}{ After Applying PSO } \\
\hline & $\begin{array}{l}\text { Voltage } \\
\text { (p.u) }\end{array}$ & $\begin{array}{l}\text { Activ } \\
\text { Powe } \\
\mathrm{r}\end{array}$ & $\begin{array}{l}\text { Reactiv } \\
\text { e } \\
\text { Power }\end{array}$ & $\begin{array}{l}\text { Voltage } \\
\text { (p.u) }\end{array}$ & $\begin{array}{l}\text { Active } \\
\text { Power }\end{array}$ & $\begin{array}{l}\text { Reactive } \\
\text { Power }\end{array}$ \\
\hline 1 & 1.000 & $\begin{array}{l}236.6 \\
9\end{array}$ & -11.931 & 1.1000 & 233.6 & -32.612 \\
\hline 2 & 0.980 & $\begin{array}{l}38.03 \\
2\end{array}$ & 24.916 & 1.0900 & 38.03 & 39.016 \\
\hline
\end{tabular}




\begin{tabular}{|l|l|l|l|l|l|l|}
\hline 3 & 0.960 & 0 & 42.155 & 1.0700 & 0 & 39.671 \\
\hline 6 & 1.000 & 0 & 23.253 & 1.1000 & 0 & 13.205 \\
\hline 8 & 1.000 & 0 & 15.575 & 1.1000 & 0 & 12.798 \\
\hline Cost & & $\begin{array}{l}8266 . \\
8\end{array}$ & $\begin{array}{l}3596.6 \\
4\end{array}$ & & 8145.3 & 3491.01 \\
\hline
\end{tabular}

It is seen from the table that the voltage profile has improved when we apply TVAC-PSO as shown in the figure3.1. Accordingly the cost of both the active power and reactive power has decreased drastically when calculated using the dispatch formula equation shown above. Minimum reactive power cost also implies that the system has minimum losses and thereby explains the optimal dispatch.

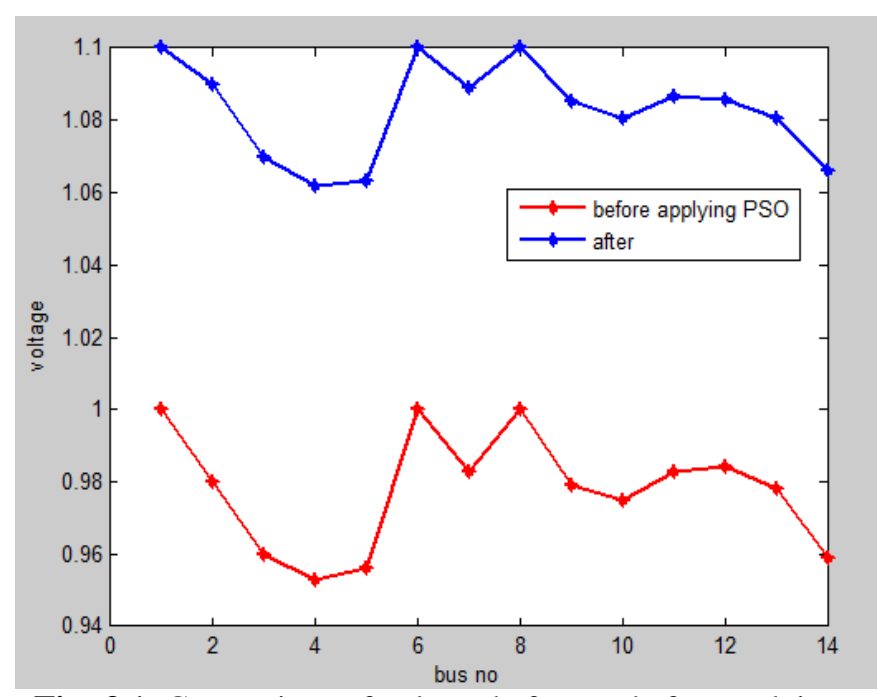

Fig -3.1: Comparison of voltage before and after applying PSO at line base loading condition

\section{Case(ii): Maximum Load Condition}

When the incremental cost is 46.698 \$MWh and the optimal dispatch of generation is $396.62 \mathrm{MW}$. The table II shows the comparison before and after applying PSO at the generators $1,2,3,6$ and 8 when the cost coefficients are, $a=$ $0.04303, b=20$ and $c=0$ at the $8^{\text {th }}$ hour and when there is maximum loading condition that is when generator 8 is at its maximum limit. It is seen from the table that the voltage profile has improved when we apply TVAC-PSO as shown in the figure 3.2. Accordingly the cost of both the active power and reactive power has decreased drastically and is shown in the same figure.

Table 2: Comparison of active and reactive power at maximum load condition

\begin{tabular}{|c|c|c|c|c|c|c|}
\hline \multirow[t]{2}{*}{ Generator } & \multicolumn{3}{|c|}{ Before Applying PSO } & \multicolumn{3}{|c|}{ After Applying PSO } \\
\hline & $\begin{array}{l}\text { Voltage } \\
\text { (p.u) }\end{array}$ & $\begin{array}{l}\text { Activ } \\
\text { e } \\
\text { Power }\end{array}$ & $\begin{array}{l}\text { Reactiv } \\
\text { e Power }\end{array}$ & $\begin{array}{l}\text { Voltag } \\
\text { e } \\
\text { (p.u) }\end{array}$ & $\begin{array}{l}\text { Active } \\
\text { Power }\end{array}$ & $\begin{array}{l}\text { Reactive } \\
\text { Power }\end{array}$ \\
\hline 1 & 1.000 & $\begin{array}{l}343.2 \\
24\end{array}$ & 0.561 & 1.100 & $\begin{array}{l}336.60 \\
3\end{array}$ & 21.990 \\
\hline 2 & 0.970 & $\begin{array}{l}53.39 \\
7\end{array}$ & 52.561 & 1.0700 & 53.397 & 33.551 \\
\hline 3 & 0.950 & 0 & 76.264 & 1.0500 & 0 & 37.955 \\
\hline
\end{tabular}

\begin{tabular}{|l|l|l|l|l|l|l|}
\hline 6 & 0.960 & 0 & 21.760 & 1.0900 & 0 & 25.067 \\
\hline 8 & 1.000 & 0 & 24.615 & 1.1000 & 0 & 22.350 \\
\hline Cost & & $\begin{array}{l}13714 \\
.2\end{array}$ & $\begin{array}{l}7025.79 \\
2\end{array}$ & & $\begin{array}{l}13388 \\
1\end{array}$ & $\begin{array}{l}4623.25 \\
4\end{array}$ \\
\hline
\end{tabular}

Accordingly the cost of both the active power and reactive power has decreased drastically when calculated using the dispatch formula equation shown above. Minimum reactive power cost also implies that the system has minimum losses and thereby explains the optimal dispatch.

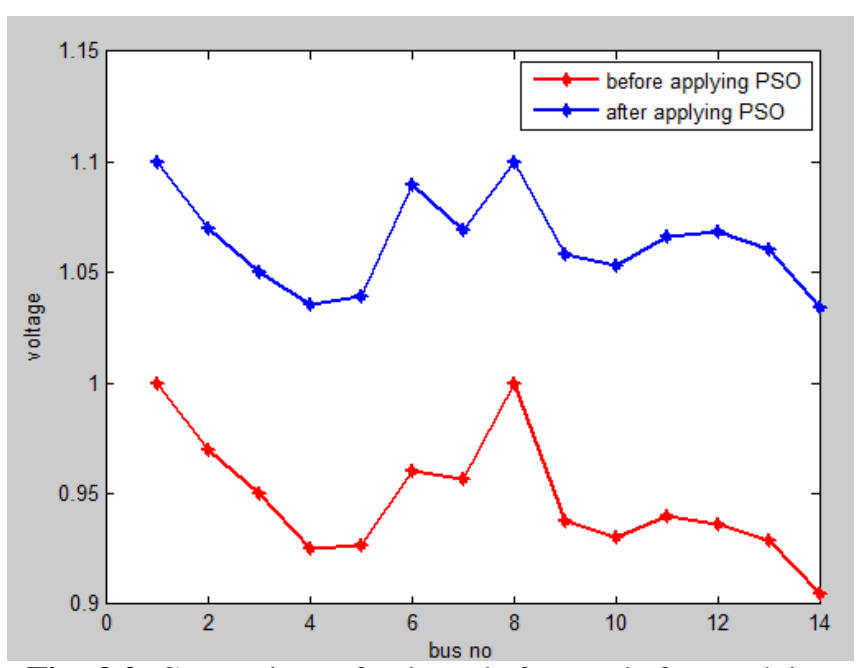

Fig-.3.2. Comparison of voltage before and after applying PSO at the maximum loading condition

\section{Case(iii): Line Contigency Condition and Base}

\section{Loading}

When the incremental cost is $39.061 \$ / \mathrm{MWh}$ and the optimal dispatch of generation is $257.05 \mathrm{MW}$ and when the lines 9 to 14 are under contingency condition. The table III shows the comparison before and after applying PSO at the generators $1,2,3,6$ and 8 when the cost coefficients are, a= $0.04303, b=20$ and $c=0$ at the $8^{\text {th }}$ hour. It is seen from the table that the voltage profile has improved when we apply TVAC-PSO as shown in the figure 3.3. Accordingly the cost of both the active power and reactive power has decreased drastically and is shown in the same figure.

Table 3: Comparison of active and reactive power at line contingency condition

\begin{tabular}{|c|c|c|c|c|c|c|}
\hline \multirow{2}{*}{$\begin{array}{l}\text { Generator } \\
\mathrm{s}\end{array}$} & \multicolumn{3}{|c|}{ Before Applying PSO } & \multicolumn{3}{|c|}{ After Applying PSO } \\
\hline & $\begin{array}{l}\text { Voltag } \\
\text { e } \\
\text { (p.u) }\end{array}$ & $\begin{array}{l}\text { Active } \\
\text { Power }\end{array}$ & $\begin{array}{l}\text { Reactiv } \\
\text { e Power }\end{array}$ & $\begin{array}{l}\text { Voltag } \\
\text { e } \\
\text { (p.u) }\end{array}$ & $\begin{array}{l}\text { Active } \\
\text { Power }\end{array}$ & $\begin{array}{l}\text { Reactiv } \\
\text { e Power }\end{array}$ \\
\hline 1 & 1.000 & $\begin{array}{l}237.02 \\
6\end{array}$ & -31.244 & 1.1000 & $\begin{array}{l}233.98 \\
3\end{array}$ & -33.707 \\
\hline 2 & 0.990 & 38.032 & 49.108 & 1.0900 & 38.032 & 34.938 \\
\hline 3 & 0.960 & 0 & 32.097 & 1.0700 & 0 & 36.959 \\
\hline 6 & 1.000 & 0 & 18.344 & 1.1000 & 0 & 10.583 \\
\hline 8 & 1.000 & 0 & 6.243 & 1.1000 & 0 & 4.491 \\
\hline Cost & & $\begin{array}{l}8280.2 \\
5\end{array}$ & 3392.02 & & \begin{tabular}{|l}
8157.7 \\
1
\end{tabular} & 2690.6 \\
\hline
\end{tabular}




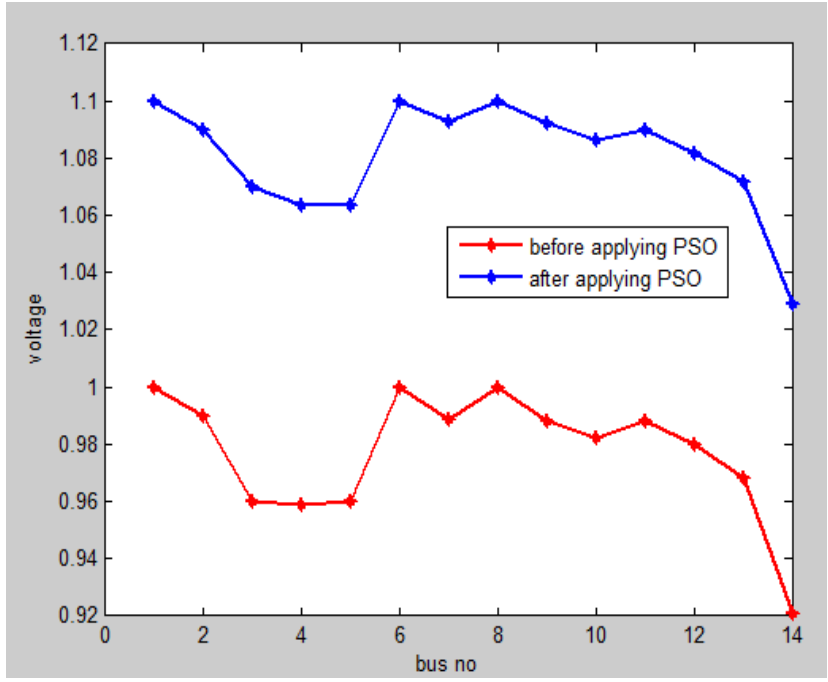

Fig-.3.3. Comparison of voltage before and after applying PSO at the line contigency condition

\section{Case(iv): Line Contigency Condition and}

\section{Maximum Loading}

When the incremental cost is $43.865 \$ / \mathrm{MWh}$ and the optimal dispatch of generation is $351.863 \mathrm{MW}$ and when the lines 9 to 14 are under contingency condition with the maximum load demand. The table IV shows the comparison before and after applying PSO at the generators 1,2,3,6 and 8 when the cost coefficients are, $a=0.04303, b=20$ and $c=0$ at the $8^{\text {th }}$ hour.

Table 4: Comparison of active and reactive power at maximum load condition

\begin{tabular}{|l|l|l|l|l|l|l|}
\hline $\begin{array}{l}\text { Generato } \\
\text { rs }\end{array}$ & \multicolumn{5}{|l|}{ Before Applying PSO } & \multicolumn{3}{l|}{ After Applying PSO } \\
\hline & $\begin{array}{l}\text { Volta } \\
\text { ge } \\
\text { (p.u) }\end{array}$ & $\begin{array}{l}\text { Active } \\
\text { Power }\end{array}$ & $\begin{array}{l}\text { Reacti } \\
\text { ve } \\
\text { Power }\end{array}$ & $\begin{array}{l}\text { Volta } \\
\text { ge } \\
\text { (p.u) }\end{array}$ & $\begin{array}{l}\text { Active } \\
\text { Power }\end{array}$ & $\begin{array}{l}\text { Reactiv } \\
\text { e } \\
\text { Power }\end{array}$ \\
\hline 1 & 1.000 & 304.132 & 2.014 & $\begin{array}{l}1.100 \\
0\end{array}$ & 298.564 & 2.986 \\
\hline 2 & 0.970 & 47.731 & 31.712 & $\begin{array}{l}1.080 \\
0\end{array}$ & 47.731 & 29.737 \\
\hline 3 & 0.950 & 0 & 61.037 & $\begin{array}{l}1.050 \\
0\end{array}$ & 0 & 34.493 \\
\hline 6 & 0.970 & 0 & 26.174 & $\begin{array}{l}1.080 \\
0\end{array}$ & 0 & 23.532 \\
\hline 8 & 1.000 & 0 & 16.764 & $\begin{array}{l}1.100 \\
0\end{array}$ & 0 & 16.178 \\
\hline Cost & & $\begin{array}{l}11586.9 \\
37\end{array}$ & $\begin{array}{l}4866.1 \\
6\end{array}$ & & $\begin{array}{l}11331.1 \\
76\end{array}$ & $\begin{array}{l}3558.1 \\
99\end{array}$ \\
\hline
\end{tabular}

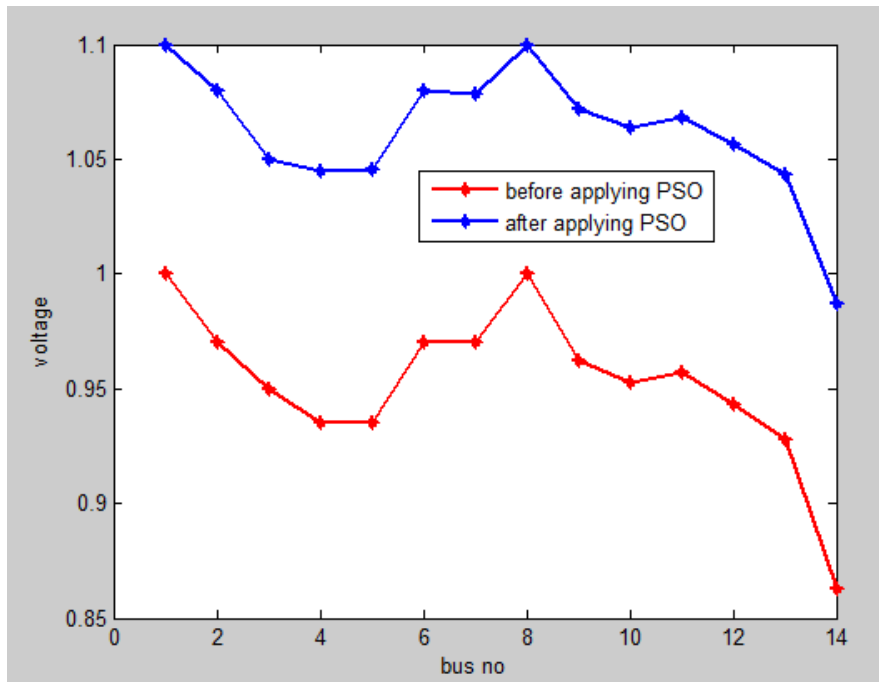

Fig.3.4. Comparison of voltage before and after applying PSO at the line contigency and maximum loading condition together

Table 5: Load profile

\begin{tabular}{|c|c|c|}
\hline Hours & Load Scaling Factor & Load \\
\hline 1 & .790 & 217.065 \\
\hline 2 & .780 & 214.372 \\
\hline 3 & .780 & 214.372 \\
\hline 4 & .780 & 214.372 \\
\hline 5 & .8004 & 219.918 \\
\hline 6 & .842 & 231.277 \\
\hline 7 & .915 & 251.447 \\
\hline 8 & 1 & 274.726 \\
\hline 9 & 1 & 274.726 \\
\hline 10 & .957 & 263.013 \\
\hline 11 & .937 & 257.451 \\
\hline 12 & .915 & 251.477 \\
\hline 13 & .894 & 245.665 \\
\hline 14 & .873 & 239.898 \\
\hline 15 & .852 & 234.147 \\
\hline 16 & .863 & 237.021 \\
\hline 17 & .863 & 237.021 \\
\hline 18 & .873 & 239.898 \\
\hline 19 & .936 & 257.246 \\
\hline 20 & .926 & 254.345 \\
\hline 21 & .905 & 248.554 \\
\hline 22 & .884 & 242.78 \\
\hline 23 & .884 & 242.78 \\
\hline 24 & .884 & 242.78 \\
\hline
\end{tabular}

The load profile of IEEE14 bus system for twenty four hours with the load scale factor and base loading condition is shown in table $\mathrm{V}$. 


\section{CONCLUSION}

In this paper, a complete methodology is proposed for reactive power pricing in a deregulated electricity market. The problem of optimal power dispatch is solved using time-varying acceleration coefficients particle swarm optimization (TVAC-PSO), which is far better than conventional power flow analysis techniques because of its convergence at the global best rather than converging at the local best. The dispatch problem is divided into two subproblems as real power dispatch and reactive power dispatch. Total reactive power cost consists of unused capacity, costs of direct reactive power consumption and the cost of voltage control. The cost component of reactive power output is tested on the modified IEEE 14-bus.The future scope includes taking into consideration various reactive power compensating devices such as capacitors or any FACT device.

\section{ACKNOWLEDGEMENTS}

I dedicate this part to acknowledge and thank those responsible for the shaping of this work. Without their guidance and help, the experience while doing this project would not have been so smooth and efficient. I am extremely grateful to my guide, Prof. Vara Prasad Janamala, who has supported and helped to carry out the project. His/her constant monitoring and encouragement helped me keep up to the project schedule. I would like to extend my sincere thanks to all the faculty members. I also like to extend thanks to my friends and family members for their continuous support.

\section{REFERENCES}

[1] Chira Achayuthakan and Weerakorn Ongsaku, "TVAC-PSO Based Optimal Reactive Power Dispatch for Reactive Power Cost Allocation under Deregulated Environment ", IEEE Trans. On Power System, 2009.

[2] S.Sakthivel and Dr. D. Mary, "Reactive Power Optimization for Voltage Stability Limit Improvement Incorporating TCSC Device through DE/PSO under Contingency Condition", IU-JEEE Vol. 12(1), (2012), 1419-1430.

[3] Garng M. Huang and H. Zhang, "Pricing of Generators reactive Power Delivery and Voltage Control in the Unbundled Environment", IEEE Trans. On Power System, 2000

[4] Chira Achayuthakan and Weerakorn Ongsaku, "TVAC-PSO Based Optimal Reactive Power Dispatch for Reactive Power Cost Allocation under Deregulated Environment ", IEEE Trans. On Power System, 2009.

[5] http://nptel.ac.in/courses/108107028/module6/lecture 9/lecture9.pdf

[6] Weerakorn Ongsakul and Dieu Ngoc Vo, “ Artificial intelligence in Power System optimization”, Optimal reactive power dispatch, (pp 328-365)

[7] Okwe Gerald Ibe and Akwukwaegbu Isdore Onyema," Concepts of Reactive Power Control and
Voltage Stability Methods in Power System Network",IOSR Journal of computerEngineering (IOSR-JCE)e-ISSN:2278-0661,p-ISSn:2278- 8727 Volume 11,Issue 2(May-Jun.2013)

[8] Shangyou Hao and Alex Papalexopoulos, "Reactive Power Pricing and Management", IEEE Trans. On Power Systems, Vol.12.No.1, February. 